\title{
Shackling Ulcer: an Upper Extremity Ulcer Secondary to Handcuffs
}

\author{
Lawrence A. Haber, MD® and Meghan O'Brien, MD, MBE
}

Division of Hospital Medicine, Department of Medicine, San Francisco General Hospital and Trauma Center, University of California, San Francisco, San Francisco, CA, USA.

J Gen Intern Med 36(7):2146

DOI: $10.1007 / \mathrm{s} 11606-021-06654-3$

(c) Society of General Internal Medicine 2021

\begin{abstract}
A 42-year-old man with post-traumatic stress disorder presented for a mental health emergency. He was placed in custody when police identified an outstanding warrant for arrest and shackled with metal cuffs to the hospital bedframe. Physical examination of the limbs on hospital day 2 revealed a linear, circumferential stage 2 pressure ulcer of the wrist at the shackle site (Fig. 1). The patient was diagnosed with a shackling ulcer. The treating team requested the custody officer loosen the handcuff ratchet teeth. The patient was monitored
\end{abstract}

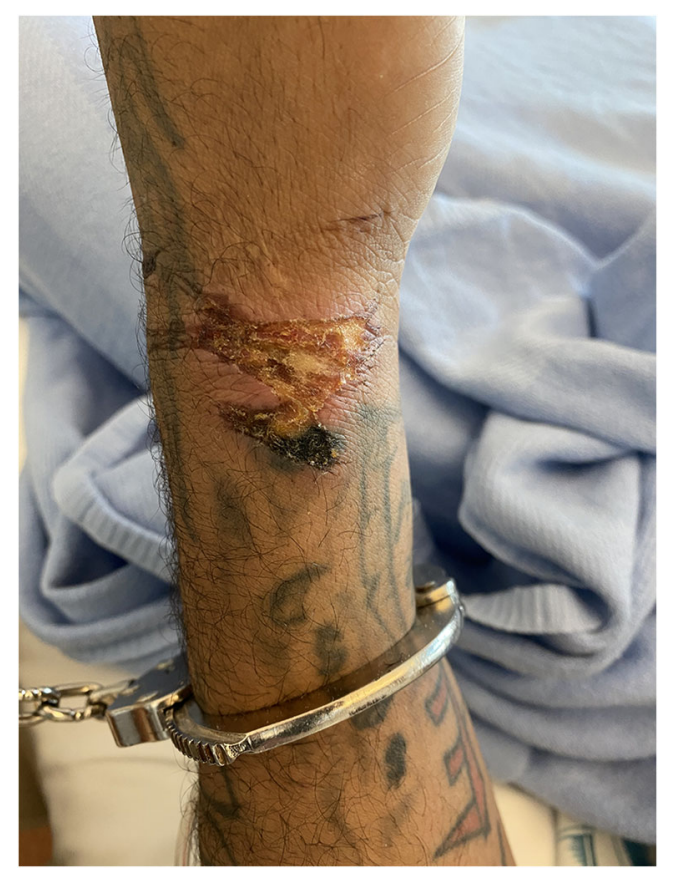

Fig. 1 Linear, circumferential stage 2 pressure ulcer of the wrist at the shackle site during physical examination on hospital day 2

Received November 20, 2020

Accepted February 3, 2021

Published online February 24, 2021 for infection and underwent local wound care with hydrocolloid dressings.

Shackling refers to restraint using a mechanical device to control the movement of a prisoner's body. Shackling can reduce mobility, impede examination, limit safe positioning, and impair healthcare provider empathy towards incarcerated patients. ${ }^{1-3}$ Case reports have described overtightening of handcuffs resulting in local tissue damage, fractures, and compressive neuropathies. ${ }^{4}$ While typical hospital restraint regulations mandate the least restrictive form that protects patient and staff safety, no such guidelines govern hospital shackling. ${ }^{5}$ As shackles are placed for nonmedical reasons, treating clinicians should carefully examine incarcerated patients with wrist and hand symptoms, and request an alternate means of securing an incarcerated patient when medically necessary.

Corresponding Author: Lawrence A. Haber, MD; Division of Hospital Medicine, Department of Medicine, San Francisco General Hospital and Trauma Center, University of California, San Francisco, San Francisco, CA, USA (e-mail: lawrence.haber@ucsf.edu).

\section{Declarations:}

Conflict of Interest: The authors report no conflicts of interest.

\section{REFERENCES}

1. Committee Opinion No. 511: Health Care for Pregnant and Postpartum Incarcerated Women and Adolescent Females, Obstetrics \& Gynecology: November 2011 - Volume 118 - Issue 5 - p 1198-1202 doi: https://doi.org/ 10.1097/AOG.0b013e31823b17e3

2. Smith FD. Perioperative care of prisoners: providing safe care. AORN J. 2016;103(3):282-288.

3. Zust BL, Busiahn L, Janisch $\mathbf{K}$. Nurses' experiences caring for incarcerated patients in a perinatal unit. Issues Ment Health Nurs. 2013;34(1):2529.

4. Haddad FS, Goddard NJ, Kanvinde RN, Burke F. Complaints of pain after use of handcuffs should not be dismissed. BMJ. 1999;318(7175):55.

5. Haber LA, Erickson HP, Ranji SR, Ortiz GM, Pratt LA. Acute Care for Patients Who Are Incarcerated: A Review. JAMA Intern Med. 2019;179(11):1561-1567.

Publisher's Note: Springer Nature remains neutral with regard to jurisdictional claims in published maps and institutional affiliations. 